\title{
INCIDENTALLY DETECTED CONGENITALLY ABSENT LEFT CIRCUMFLEX ARTERY BY MDCT CORONARY ANGIOGRAM
}

\author{
Anitha Christina1, Senthil Kumar Aiyappan², Bulabai Karpagam ${ }^{3}$
}

1 Junior Resident, Department of Radiodiagnosis, SRM Medical College Hospital and Research Centre, Kancheepuram, Tamilnadu. 2Professor, Department of Radiodiagnosis, SRM Medical College Hospital and Research Centre, Kancheepuram, Tamilnadu. 3Professor, Department of Radiodiagnosis, SRM Medical College Hospital and Research Centre, Kancheepuram, Tamilnadu.

HOW TO CITE THIS ARTICLE: Christina A, Aiyappan SK, Karpagam B. Incidentally detected congenitally absent left circumflex artery by MDCT coronary angiogram. J. Evolution Med. Dent. Sci. 2018;7(10):1298-1299, DOI: 10.14260/jemds/2018/296

\section{PRESENTATION OF CASE}

A 54-year-old male patient came to Radiology Department for MDCT coronary angiogram as routine master health checkup. The patient had no complaints of chest pain. His blood pressure was 126/82 mmHg. The patient had no history of diabetes or any other illness. His blood investigations like complete blood count, renal and liver function tests were normal. As the patient requested for CT coronary angiography as part of health check-up, it was done.

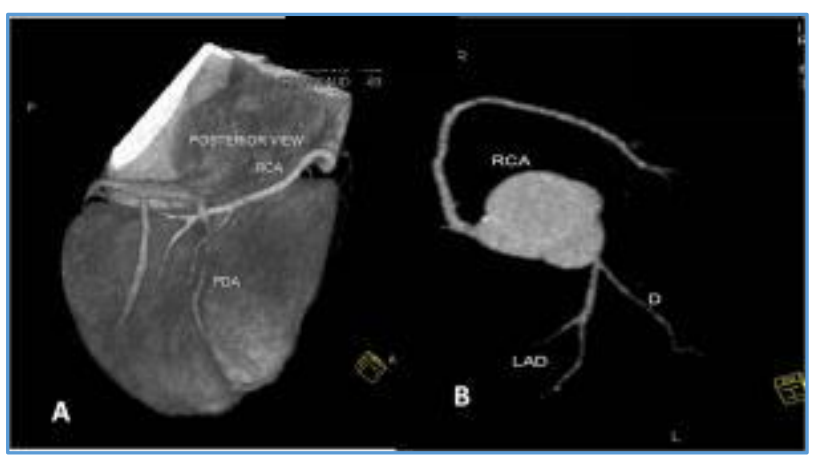

Figure 1A and B. 40-Year-Male with Chest Pain for evaluation detected to have Absent Left Circumflex Artery: 3-D Volume rendered CT Coronary Angiography Images showing Absent Left Circumflex Artery

\section{PATHOLOGICAL DISCUSSION}

MDCT coronary angiography was done on 128-slice CT scanner, which showed absent left circumflex artery with normal right coronary artery and left anterior descending artery (Fig. 1). The diagonal branches from left anterior descending artery were normal. The lateral wall of left ventricle was supplied by right coronary artery branches. After this finding, the patient underwent electrocardiography and echocardiogram. Electrocardiogram was normal and echocardiogram showed normal ejection fraction of $68 \%$ with no other significant findings. The cardiac enzymes were normal. Cardiovascular examination showed normal S1 and S2 sounds with no evidence of any additional sounds or murmur. Hence, we concluded this is a case of asymptomatic incidentally detected congenital absent left circumflex artery.

'Financial or Other Competing Interest': None.

Submission 28-11-2017, Peer Review 06-01-2018,

Acceptance 12-01-2018, Published 05-03-2018.

Corresponding Author:

Dr. Senthil Kumar Aiyappan,

Professor, Department of Radiodiagnosis,

SRM Medical College Hospital and Research Centre,

Kattangulathur, Potheri, Kancheepuram-603203,

Tamilnadu

E-mail: senthilkumarpgi@yahoo.co.in

DOI: $10.14260 /$ jemds $/ 2018 / 296$

(c) $(i)(9)$

\section{DIFFERENTIAL DIAGNOSIS}

There was no other differential diagnosis on MDCT Coronary angiography.

\section{DISCUSSION OF MANAGEMENT}

Congenital coronary artery anomalies are rare conditions, which can be clinically silent. For several decades diagnosis of coronary artery anomalies has been made with conventional angiography. However, this imaging technique has limitations due to its projectional and invasive nature.[1] Multidetector computed tomography (MDCT) allows accurate and noninvasive depiction of coronary and pulmonary artery anomalies of origin, course and termination. Multidetector row CT is superior to conventional angiography in delineating the ostial origin and proximal path of an anomalous coronary.[1-3] Understanding the computed tomographic findings of various coronary and pulmonary artery anomalies is important for treatment planning and establishment of accurate diagnosis. In this case report, we describe a rare case of incidentally detected congenitally absent left circumflex artery.

Anomalous coronary arteries are found in $0.1 \%-1.3 \%$ of the population.[4] Such anomalous branches may be associated with congenital heart disease or occur in isolation. Three broad categories in classifying anomalous origin of coronary artery include anomalous aortic origin, anomalous aortic origin with anomalous proximal course and anomalous origin from the pulmonary artery.[1-3] The most common congenital anomaly is separate origin of the left anterior descending artery and circumflex artery from the left coronary sinus.[4] The left main coronary artery or left anterior descending artery arising from the right coronary sinus of Valsalva and right coronary artery originating from the left coronary sinus of Valsalva may be associated with sudden cardiac death, hence deserve special attention.[4] Congenitally absent left circumflex artery is an extremely rare anomaly of coronary arteries with only a small number of cases having been reported, but its incidence is increasing due to the wide use of MDCT coronary angiography.[5,6] The incidence of congenitally absent left circumflex artery is between $0.003 \%$ to $0.067 \% .{ }^{[5,6]}$ Usually, in these cases the lateral wall of the left ventricle is supplied by the right coronary artery branches like in our case or by diagonals from left anterior descending artery. Congenital absence of left circumflex artery is an incidental benign finding on coronary angiography and most of these patients present with chest pain on exertion. ${ }^{[7-11]}$ Varela et al[7] reported a case of congenitally absent left circumflex with block of right coronary artery causing inferolateral and posterior wall myocardial infarction. The various investigations available to diagnose this rare entity include transthoracic, transoesophageal echocardiography, cardiac magnetic 
resonance imaging, MDCT coronary angiography and invasive coronary angiography. The best among these investigative modalities are CT coronary angiogram and invasive coronary angiogram. CT coronary angiogram is non-invasive and can provide three dimensional images like in our case.

Congenital absence of left circumflex artery is a very rare coronary artery anomaly and is usually incidentally detected during various cardiac imaging modalities. Multidetector Coronary CT (MDCT) angiography can demonstrate both the primary and secondary features of coronary artery anomaly in 3-dimensional projection, thereby helping the surgeon. MDCT depict these anomalies with high accuracy and provides high-resolution 3D data sets that allow precise definition of 3D spatial relations of the anomalies. Increased use of MDCT in cardiac imaging highlights the value of recognising such anomalies on cross-sectional, multiplanar, and volume-rendered reconstructions.

\section{REFERENCES}

[1] Kang JW, Seo JB, Chae EJ, et al. Coronary artery anomalies: classification and electrocardiogram-gated multi-detector computed tomographic findings. Seminars in Ultrasound, CT and MR 2008;29(3):18294.

[2] Kim SY, Seo JB, Do KH, et al. Coronary artery anomalies: classification and ECG-gated multi-detector row CT findings with angiographic correlation. Radiographics 2006;26(2):317-34.

[3] Dodd JD, Ferencik M, Liberthson RR, et al. Congenital anomalies of coronary artery origin in adults: 64MDCT appearance. AJR Am J Roentgenol 2007;188(2):W138-46.
[4] Yildiz A, Okcun B, Peker T, et al. Prevalence of coronary artery anomalies in 12, 457 adult patients who underwent coronary angiography. Clin Cardiol 2010;33(12):E60-4.

[5] Guo J, Xu M. Congenital absence of the left circumflex artery associated with inferior myocardial infarction. Intern Med 2012;51(1):71-4.

[6] Hongsakul K, Suwannanon R. Congenital absence of left circumflex artery detected by computed tomography coronary angiography: a case report. Case Rep Vasc Med 2012;2012:204657.

[7] Varela D, Teleb M, Said S, et al. Congenital absence of left circumflex presenting after an emotional stressor. Pol J Radiol 2015;80:529-31.

[8] Ullah S, Khan M, Khan NAJ, et al. Absence of left circumflex artery: a rare congenital disorder of coronary arteries. Case Rep Cardiol 2017;2017:8710135. doi: 10.1155/2017/8710135.

[9] Quijada-Fumero A, Pimienta-González R, RodriguezEsteban M. Absence of left circumflex with superdominant right coronary artery. BMJ Case Rep 2014;2014. pii: bcr2014206782. doi: 10.1136/bcr2014-206782.

[10] Duan QJ, Cheng HF, Jiang DM, et al. Congenital absence of left circumflex artery associated with constrictive pericarditis and thoracostomach. Acta Cardiol 2014;69(4):467-8.

[11] Hong PS, Lee YS, Lee JB. Congenital absence of the left circumflex coronary artery in a patient with acute inferior myocardial infarction. Herz 2014;39(8):957-9. 